\title{
PATRIMONIO VERSUS TURISMO: NUEVO YACIMIENTO DE CREACIÓN DE EMPLEO EN EL ANDÉVALO. HUELVA. ESPAÑA
}

\author{
Autor \\ Emilio M. Romero Macías \\ Universidad de Huelva \\ Escuela Politécnica Superior. \\ La Rábida. Huelva. España \\ romaci@uhu.es
}

\section{RESUMEN}

Las transformaciones económicas y sociales de las últimas décadas motivadas por el crecimiento de la renta, el aumento de la esperanza de vida, el mayor nivel educativo y la mayor disposición de tiempo libre, han llevado a la sociedad a demandar nuevos servicios y productos relacionados con el ocio y el tiempo libre, la cultura y el patrimonio.

La consolidación de este potencial necesita ir acompañado de instrumentos mediadores a cargo de agentes públicos y privados que deben difundir la idea de patrimonio como factor de desarrollo social y económico, eliminando las barreras psicológicas que impiden el crecimiento de la oferta y la demanda al ser percibidos estos servicios como "servicios de lujo".

Palabras clave: Patrimonio minero, Turismo, Andévalo, Empleo, Desarrollo Local 


\title{
HERITAGE VERSUS TOURISM: NEW DEPOSIT OF CREATION OF EMPLOYMENT IN THE ANDÉVALO. HUELVA. SPAIN
}

\author{
Author \\ Emilio M. Romero Macías \\ University of Huelva. \\ High Polytechnic School \\ The Rabida. Huelva. Spain \\ romaci@uhu.es
}

\begin{abstract}
The economic and social transformations of the last decades motivated by the growth of the rent, the increase of the life expectancy, the higher educational level and higher disposition of free time, have led society to demand new services and products related to leisure and free time, culture and heritage.

The consolidation of this potential needs to go hand in hand with mediating instruments under the care of public and private agents that must spread the idea of heritage as a factor of social and economic development, eliminating the psychological barriers that prevent the growth of the supply and demand from being perceived as "luxury services".
\end{abstract}

Key words: Mining heritage, Tourism, Andévalo, Employment, Local Development 


\section{INTRODUCCIÓN}

La comarca del Andévalo está situada en una de las zonas más periféricas de la Península Ibérica y de Europa. Sus límites con Portugal, alejamiento de los ejes de desarrollo y los déficits en infraestructuras, añaden efectos de perifericidad evidentes, de los que solo se propone salir recientemente con la mejora de las infraestructuras económicas y la adopción de nuevas tecnologías agrícolas que impulsen nuevos cultivos.

El poblamiento ha sufrido diversos reverses debido a la emigración, presentando un débil sistema de ciudades de escasos umbrales demográficos. Con una marcada pobreza, el Andévalo ha sido objeto de diferentes intentos para impulsar su desarrollo, no obstante pocas veces han sido coronados por el éxito. La mayoría de las ocasiones, los distintos planes de desarrollo no han tenido en cuenta los deseos de los agentes y las posibilidades que ofrecía el potencial endógeno (COPT, 1996). Por suerte, en la actualidad, se está abriendo una nueva etapa en la que se impone el paradigma del desarrollo local, que se articula en la participación de los ciudadanos, entes locales y sus organizaciones como verdaderos agentes de desarrollo, protagonistas y receptores del mismo y donde los recursos internos cobran especial importancia para mantener un crecimiento social y económico autosostenido.

Figura 1. Delimitación de la comarca del Andévalo en la provincia de Huelva, España.

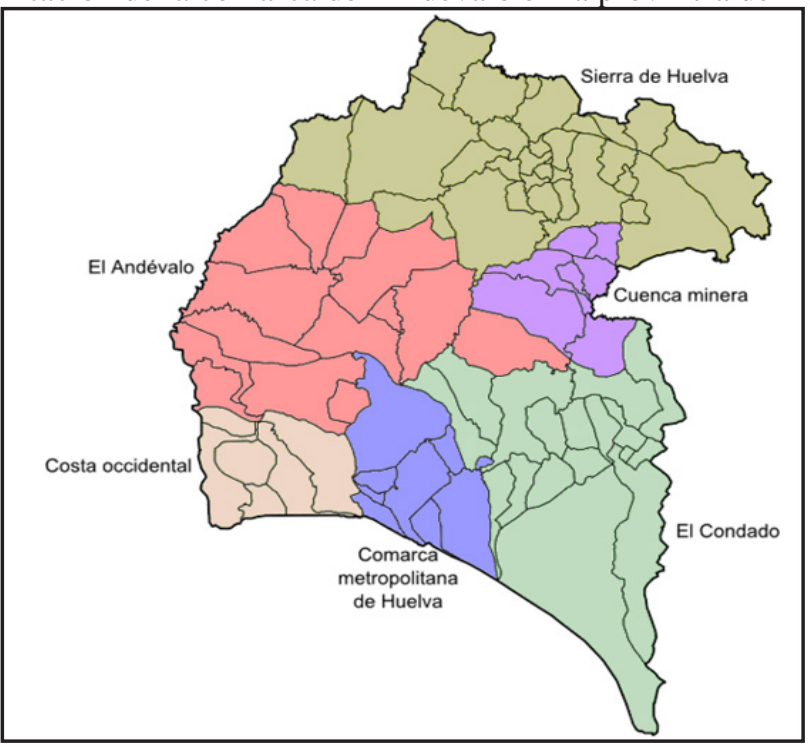


Campamentos mineros y militares fueron durante mucho tiempo los centros dinámicos y de actividad más importante. Estos poblamientos siempre han sido dispersos, especialmente condicionados por la actividad minera que necesitó fuerza laboral allí donde encontró filones de mineral. Así, los núcleos de población más antiguos suelen coincidir con la cabecera municipal y vienen acompañados de otros poblados coyunturales en el espacio y en el tiempo, pues muchos de los núcleos de población tienen su origen en campamentos de explotaciones mineras, propiedad de las compañías explotadoras.

A raíz del declive de la minería, este poblamiento se ve mermado en cuanto a los recursos económicos, comienza la emigración en busca de nuevos recursos y existe un estancamiento en el desarrollo de la comarca, donde sólo han quedado los restos de los vestigios de una gran actividad minera durante décadas.

\section{EL PATRIMONIO MINERO-INDUSTRIAL}

El Patrimonio Industrial está constituido por los bienes muebles e inmuebles generados, en el transcurso histórico, por las actividades extractivas y productoras del hombre. Estos bienes patrimoniales se insertan en un paisaje o entorno determinado que también ha de ser objeto de protección debido a que la industria es una consecuencia directa del uso que la sociedad hace del medio natural.

En la década de los 70, es el momento de las reconversiones, el objetivo prioritario es la conservación y se plantea que es lo que hay que hacer tanto con el patrimonio como con el excedente humano que generan las áreas en crisis. El Patrimonio Industrial deja de ser una rémora para las administraciones y se convierte en un instrumento de desarrollo local. Patrimonio "cultural”, tanto histórico como industrial, y tanto material como inmaterial pasan a formar el eje central de grandes proyectos turísticos (Parque Minero de Riotinto, Museo del Carbón en Asturias, Museo de la Ciencia y de la Técnica en Cataluña, Museo del Ferrocarril en Gijón, etc.).

La gestión del Patrimonio Cultural, orientado casi siempre hacia el Turismo, se ha convertido en un instrumento dinamizador de Desarrollo Local en las zonas donde los sectores económicos tradicionales han entrado en franca fase degenerativa.

En Andalucía tenemos numerosas muestras de proliferación de ideas y multiplicidad de soluciones para superar la decadencia económica. En el caso de Río Tinto como consecuencia de la crisis galopante de la minería del cobre, el Patrimonio Cultural se está utilizando como recurso de desarrollo endógeno. La industrialización y los testimonios de la historia social y de la técnica, han dejado de ser una rémora y se han convertido en 
recursos para el desarrollo local, con fines culturales y turísticos.

La preservación del patrimonio industrial no se puede realizar siguiendo las pautas de la del patrimonio artístico, donde cada pieza tiene un valor de por sí y se supone que se conservan porque son unas obras que expresan la máxima creatividad humana y por esto cada una de ellas son unas realizaciones excepcionales que la sociedad actual ha sacralizado.

Una de las mejores situaciones para el Patrimonio Industrial es cuando se puede convertir en museo. En este caso se ha de saber muy claramente lo que se quiere comunicar ya que la simple exposición de los objetos puede tener unos resultados muy pobres porque no son objetos para ser únicamente contemplados; en cambio, cada objeto o cada conjunto de ellos pueden explicar una cantidad de cosas diferentes.

Es evidente que no es posible convertir todos los edificios industriales en museos y que por lo tanto la preservación de un número importante de elementos del Patrimonio Industrial ha de realizarse a través de la reutilización para otras funciones, sean públicas o privadas. Hay una importante cantidad de ejemplos de edificios industriales convertidos en escuelas, centros de ocio, viviendas, lugares comerciales, etc. que se erigen como testimonio del proceso industrial.

La visión sobre el patrimonio debe ser flexible y dinámica, ya que queremos identificar en ella al conjunto de elementos y prácticas sociales a través de los cuales un colectivo pretende reconocerse y representarse. De esta forma, según nuestra concepción, el patrimonio adquiere sentido pleno como parte de los procesos de identificación colectiva.

En definitiva entendemos Patrimonio en su acepción más amplia de "Patrimonio Cultural", planteado en la Conferencia Mundial de la UNESCO en México, en 1982, con la siguiente definición:

“ El Patrimonio Cultural de un pueblo comprende las obras de sus artistas, arquitectos, músicos, escritores y sabios, así como las creaciones anónimas, surgidas del alma popular, y el conjunto de valores que dan sentido a la vida, es decir, las obras materiales y no materiales, que expresan la creatividad de ese pueblo; la lengua, los ritos, las creencias, los lugares y monumentos históricos, la literatura, las obras de arte y los archivos y bibliotecas" (UNESCO 1982).

Desde una perspectiva etnológica la Cuenca Minera de Tharsis es, dentro de Huelva, una de las zonas donde más profundamente se ha desarrollado la cultura minera, 
valdría decir dónde la cultura minera se ha manifestado de manera más explícita, continuada y rica. De ahí la oportunidad de la declaración de la comarca como Bien de Interés Cultural en su categoría de Sitio Histórico (Pérez López, et al., 2003), por su incidencia en el conjunto de la cultura y la historia de Andalucía.

\section{PATRIMONIO Y EMPLEO}

J. Delors, consciente de las transformaciones económicas y sociales en las últimas décadas, elaboró durante su presidencia de la Unión Europea en 1993 el Libro Blanco "Crecimiento, competitividad y empleo. Retos y pistas para entrar en el siglo $X X I$ ", en el que enumeraba los 17 sectores productivos que se beneficiarían de estos cambios y a los que denominó nuevos yacimientos de empleo. Entre ellos incluyó la valorización del patrimonio cultural y el desarrollo cultural local. Este documento ha servido de base teórica a todos los estudios posteriores que han intentado analizar la relación patrimonio-empleo.

En España, a pesar de ser el país con más declaraciones de Patrimonio Mundial de la UNESCO, el potencial generador de empleo del patrimonio está menos desarrollado que en otros países de la Unión Europea como Francia o Inglaterra. Sin embargo, en los últimos años se detecta una mayor toma de conciencia de la infrautilización de esos recursos patrimoniales y la urgente necesidad de su puesta en valor para poder hacer frente al mercado existente. Estas circunstancias han favorecido la creación de empleo, tanto directo como indirecto, en actividades vinculadas a:

- Interpretación del patrimonio

- Creación y restauración de emplazamientos

- Difusión (Museos, Centros de interpretación,...)

- Mantenimiento de emplazamientos.

Se debe favorecer el acceso de todos al concepto de Patrimonio en sentido amplio, con el fin de que sea abandonada la idea generalizada que relaciona exclusivamente patrimonio con monumentos históricos-artísticos.

En el caso concreto del patrimonio cultural, éste encierra múltiples facetas a la hora de influir en ese campo tan preciado y necesario como es el mercado laboral. Entre los distintos perfiles profesionales y las diferentes salidas que ofrece el tema del patrimonio cultural, aparece la categoría del turismo cultural, que brinda uno de los campos más dinámicos y productivos, aunque también se muestre como uno de los más complejos y contradictorios.

En este sentido, se hace necesario ver y estudiar el patrimonio cultural como un 
factor de actividad económica y generador de empleo, y hacerlo con la misma rigurosidad y cientificidad con que se estudia el mercado laboral en cualquier otro sector de actividad económica de una comarca; por ejemplo, en el sector minero, o pesquero, o agrícola o industrial. También en el campo que nos ocupa hay empleos directos, indirectos e inducidos, y hay factores sociológicos, psicológicos, macro y microeconómicos que actúan sobre el patrimonio local a la hora de su puesta en valor. Por ejemplo, ¿qué beneficio económico ha producido el Museo Guggenheim de Bilbao en las empresas domiciliadas o instaladas en Bilbao al mejorar la imagen de la ciudad? ¿Es posible hacer la misma pregunta para el Museo Casa Dirección y las empresas de calzado y mueble de Valverde del Camino (Huelva), o para el Museo del Vino en Bollullos Par del Condado (Huelva) en relación a las bodegas productoras de la Denominación de Origen Vinos del Condado de Huelva?. Estos estudios no se realizan pero son posibles. Son necesarios para conocer las posibilidades de los recursos endógenos, y no permanezcan ociosos, especialmente en comarcas que no se pueden permitir el lujo de no sacar partido a sus posibilidades. Las mismas técnicas del marketing y de los estudios de mercado pueden ofrecer datos sobre estos aspectos.

En este sentido están los empleos directos: los profesionales adscritos a los museos y a las instituciones del patrimonio cultural, los intérpretes del patrimonio, los gestores culturales, entre otros. Igualmente existen empleos directos en el sector del turismo, que es considerado tradicionalmente como el relacionado con las empresas alojativas, las agencias de viajes y, de manera algo confusa, los bares y restaurantes. Las influencias de la actividad turística en la economía de un territorio es tal que es realmente difícil separar del sector otras actividades que pasan a la categoría de indirectas respecto a su clasificación turística. El carácter inducido que se le otorga a otras actividades es el saco en el que caben las que se distancian de lo considerado tradicionalmente como actividad turística. Pensemos en la venta de productos locales (artesanía, agroalimentarios, etc.) en los enclaves turísticos: ¿ los empleos en esta actividad son empleos directos del turismo, indirectos, o pertenecen a la última clasificación nombrada?. Hay que tener mucho cuidado porque nos podemos encontrar con núcleos turísticos en el que la generación de empleo menor viene provocada por los servicios alojativos.

Pero sea cual sea el concepto de actividad turística y qué negocios entran en este sector, hay que dejar claro la relación entre patrimonio cultural y turismo cultural. También que los actuantes en este último son actores del primero igual que lo puede ser un conservador o un intérprete del patrimonio, u otro que pudiera encontrarse en la frontera conceptual del turismo, o del turismo cultural respecto del patrimonio cultural. 


\section{EL PATRIMONIO MINERO COMO RECURSO}

La crisis de la minería de la franja pirítica onubense, que está llegando a sus límites en la actualidad, se viene padeciendo fundamentalmente, desde 1982. Está ocasionando, en la Cuenca de Tharsis, grandes problemas estructurales, como altas tasas de desempleo, desactivación económica de otros sectores subsidiarios de la minería, fuerte emigración de los tramos jóvenes de la población, etc. Lo que, unido a la histórica descentralización, marcada por la inexistente planificación de actividades económicas y empresariales alternativas, desde las administraciones en el pasado, hace que los instrumentos de desarrollo local utilizados recientemente no estén obteniendo los resultados apetecidos.

Cualquier análisis serio que se haga en la cuenca, para la búsqueda de alternativas, va a determinar que tanto el territorio como la población han estado marcados tradicionalmente por las explotaciones mineras.

El patrimonio minero de Tharsis, que hasta hacía muy poco tiempo tenía carácter puramente arqueológico, se está conceptualizando igualmente como paisajístico, etnográfico, antropológico, histórico y sobre todo industrial.

La visión sobre el patrimonio debe ser flexible y dinámica, ya que queremos identificar en ella al conjunto de elementos y prácticas sociales a través de los cuales un colectivo pretende reconocerse y representarse. De esta forma, según nuestra concepción, el patrimonio adquiere sentido pleno como parte de los procesos de identificación colectiva.

El Patrimonio Cultural de Tharsis, está constituido por los bienes, tanto materiales (fábricas, edificios, maquinarias, instalaciones mineras, sistemas de explotación, etc.), como inmateriales (tradiciones, costumbres, culturas, etc.), generados en un proceso histórico para la explotación de un medio natural, rico en minerales, conformando un paisaje industrial por la acción antrópica del hombre, que también adquiere una dimensión patrimonial que debe ser preservada y explicada (Romero Macías, et al., 2010).

Aunque la Administración no contempla en el enunciado de la ley el concepto de patrimonio industrial explícitamente, entendemos que éste va incluido en el patrimonio etnográfico y en el patrimonio científico-técnico, ambos contemplados en la legislación.

Hacia 1980, en la cuenca minera de Riotinto, ante este cúmulo de circunstancias adversas, la Administración, las instituciones locales, la propia empresa (Río Tinto Minera, S.A.), etc., establecieron otras vías de desarrollo a implantar en la comarca, 
fundamentalmente con una política de subvenciones para la creación de pequeña y mediana empresa y la implantación del turismo cultural como desarrollo endógeno, o dicho de otra forma "patrimonio histórico" como activo de desarrollo.

Las líneas básicas de actuación se pueden encuadrar en los siguientes apartados:

- Conservación y restauración del patrimonio cultural e histórico, tanto desde el punto de vista arqueológico como industrial.

- Estudio e investigación de la Historia de la Minería a través de los restos materiales e inmateriales que se han ido imbricando en un proceso histórico siempre relacionado con la minería.

- Regeneración del conjunto medioambiental ambiental.

- Difusión de los valores históricos culturales que encierra el mencionado conjunto ambiental, con programas formativos y educacionales.

Es por ello que no se debe confundir "Patrimonio minero" con Turismo en las minas. Se podría teorizar mucho sobre estos conceptos, no es el momento, pero si puntualizar que el patrimonio está constituido por los bienes muebles, inmuebles y bienes inmateriales generados, en el transcurso histórico, por las actividades extractivas y productoras del hombre. Estos bienes patrimoniales se insertan en un paisaje o entorno determinado, que también ha de ser objeto de protección, debido a que la industria es consecuencia directa del uso que la sociedad hace del medio natural, y es reflejo de cómo incide en la transformación de éste, no solo como elemento susceptible de su puesta en valor desde el punto de vista turístico.

Estaremos de acuerdo que la actividad minera había ordenado la vida, las costumbres y hasta el sentir de toda una comarca durante toda la historia; por lo que se hace necesario, a partir de la crisis minera y de la consiguiente pérdida de sus valores intrínsecos, las asociaciones, empresas e instituciones que promuevan y canalicen las acciones socio-culturales en nuestro territorio minero, actuando desde el referente identificador de Patrimonio minero.

En las acciones que se planteen debe primar la preocupación por la preservación y conservación de nuestro patrimonio histórico minero, y no tan solo su puesta en valor, ya que no siempre es lo más recomendable. 


\section{EL TURISMO CULTURAL COMO GENERADOR DE EMPLEO: PERFILES SOCIO-LABORALES}

Los rasgos del turismo cultural encajan con las características del sector servicio en general, en el que naturalmente se incluye todas las tipologías de turismo. Los servicios contienen el mayor porcentaje de empleos de la Unión Europea con un crecimiento sostenido del 2’5\% en los últimos diez años, frente al 0’5\% de otros sectores de actividad. Dentro de aquel, el sector de la cultural y el ocio aumento hasta un 5\% anual.

Las transformaciones de la sociedad europea está propiciando los cambios de hábitos y necesidades, adquiriendo la cultural, el ocio y el medioambiente uno de los factores preeminentes en la vida de los ciudadanos europeos. El estudio de estas necesidades llevó a la Comisión Europea ha establecer campos de actividad con grandes posibilidades de generación de empleo, acuñando el concepto de Nuevos Yacimientos de Empleo (NYE). Este concepto se basaba en el aprovechamiento óptimo del gran mercado buscando sus nuevas necesidades. En concreto, fueron 17 campos entre los que se encontraba el turismo y el patrimonio cultural junto con el desarrollo de actividades culturales locales. Desde luego, no era misión de este Documento de la Unión Europea, denominado Libro Blanco, la de elaborar el concepto de turismo cultural ni otorgarle valor sobre otros conceptos afines de turismo. Lo que sí estaba claro era que la actividad turística en torno al patrimonio cultural era uno de esos NYE.

Casi diez años después, un estudio del Círculo de Progreso dado a conocer hace pocas semanas, establece 21 Yacimientos de Empleo, siendo 3 de ellos en torno a la Sociedad del Ocio. No obstante, este estudio no contempla aquellas actividades reconducibles al turismo cultural, lo cual nos alerta sobre el posible cambio de actitudes en el mercado (o en los intereses de los investigadores...).

El patrimonio cultural genera múltiples actividades que pueden ser agrupadas en torno a perfiles profesionales de gran heterogeneidad: arqueólogos, antropólogos, arquitectos, ingenieros, juristas, historiadores, geógrafos, economistas, restauradores.. Una variada gama de profesiones se ocupan diariamente de la conservación, difusión, gestión, en definitiva, dinamización y puesta en valor de nuestro patrimonio cultural.

A pesar de este perfil heterogéneo del personal relacionado con el patrimonio cultural, el mercado laboral viene marcado por un rasgo fundamental y es que el principal contratante es la Administración Pública. Tradicionalmente, este ámbito se caracteriza por la funcionarización. No obstante, se puede comprobar cómo el mercado de trabajo se transforma alterando sus características aunque debido a la paradoja de la mayor precariedad del empleo público, según lo cual, las administraciones tienden mucho más 
a contratar laboralmente de manera temporal o en régimen de interinidad. Sigue siendo, de todos modos, el sector público el principal generador de empleo con diferencia en el terreno del patrimonio cultural.

Desde el sector privado se observan algunas variaciones en las que en la mayor parte de las veces la Administración Pública cambia su condición de empleador por la cliente de los servicios que contrata a empresas, formadas éstas muchas veces por un profesional que ejerce de empresario individual. Encontrar la participación del sector privado de manera exclusiva es algo extraño en esta materia, lo que es razonable si reconocemos que la titularidad da rasgo al patrimonio cultural que tiene siempre una connotación, cuando no pública, de limitación al ejercicio del derecho de propiedad.

En este sentido, el ámbito más importante de actividad privada en torno al patrimonio cultural lo encontramos en el turismo. Este sector genera el mayor número de empleos en torno al patrimonio cultural y representa, por tanto, el máximo exponente de la vertiente económica del patrimonio cultural en el momento en que revierte a la comunidad creando riqueza.

El turismo es uno de los sectores más dinámicos desde el punto de vista del empleo. Además, genera más empleo en colectivos con mayores dificultades laborales: los jóvenes y las mujeres. Estas últimas obtienen una horquilla de entre el 45 y el $65 \%$ de estos puestos.

La extensión de los servicios que abarca el turismo cultural facilita la creación de nuevos empleos que se caracterizan básicamente por:

- Una fuerte presencia de empleados o emprendedores que provienen de colectivos con dificultades de inserción profesional (jóvenes, mujeres).

- Una demanda significativa de personal con alto nivel de cualificación.

- Una frecuencia del trabajo a tiempo parcial más elevada que en los otros sectores.

- Una proporción elevada de trabajadores independientes y de iniciativas muy pequeñas.

Junto a los perfiles tradicionales del sector turístico que absorben las agencias de viajes, los hoteles, los transportes y los establecimientos de restauración (restaurantes, bares, etc.), encontramos figuras directamente relacionadas con el servicio específico del turismo cultural. 


\section{LA INTERPRETACIÓN DEL PATRIMONIO Y EL TURISMO: Una relación común y desconocida}

La conservación y rehabilitación del patrimonio histórico, entendido no sólo como patrimonio arquitectónico o artístico sino como patrimonio integrado, es el segundo yacimiento de empleo en Europa.

Según el informe Series ECON 106A de la CE 2, el patrimonio, junto a otros elementos culturales, abarca un conjunto de actividades económicas importantes en relación con la creciente demanda cultural. Las industrias culturales se manifiestan simultáneamente como motor del empleo y catalizador de la identidad regional, nacional y europea. Para dar cauce a esas energías hay que emplear recursos humanos y financieros, que permitan compatibilizar la expansión económica con la cohesión social de la sociedad europea del III Milenio, convirtiendo la cultura en servicio público y privado económicamente rentable, al menos como intención y objetivo.

Las industrias culturales pueden posibilitar la creación de nuevos empleos, más allá de las medidas clásicas de preservación del patrimonio cultural, si se realizan estas políticas desde un enfoque integrado y global con respecto a las actividades culturales. Para apoyar de forma adecuada a las industrias culturales, es necesario que el potencial de crecimiento económico y la riqueza cultural de la Unión Europea se inviertan para el desarrollo del sector de estas industrias culturales, fomentando la creación de empresas culturales.

En el aspecto señalado anteriormente se considera que el turismo cultural podría convertirse en el punto de despegue y de refuerzo de las industrias culturales y debería permitir la consolidación y el aumento de las actividades económicas relacionadas con el patrimonio cultural. Éste puede constituirse en elemento de desarrollo "empresarial", que auspicie la cohesión económica, social y cultural de regiones menos favorecidas; en el que se incluyen la dinamización del empleo y la valoración de la cultura europea. El reclamo turismo cultural-visitas del patrimonio puede ser, por otra parte, el polo de atracción de otras demandas culturales. Pero sin olvidar nunca los perjuicios que un turismo cultural no integrado podría tener sobre el equilibrio socioeconómico de una región. Hay que cuidar que los flujos turísticos incrementen la riqueza de una zona sin hacer peligrar las idiosincrasias locales, regionales y nacionales (sostenibilidad). Esto sólo es posible si estas industrias culturales se integran en una noción más amplia del patrimonio (estrategia horizontal del turismo cultural), que puede ser la de Patrimonio Integral.

Estas industrias culturales ayudan a la creación de empleo, compatibles con la economía de mercado, y constituyen, además, un excelente recurso para reforzar el 
sentimiento de comunidad en Europa. Las industrias culturales, entonces, refuerzan la cohesión de un territorio mediante su desarrollo socioeconómico (dimensión estructuradora) y, al mismo tiempo, consolidan las identidades culturales de los pueblos europeos (dimensión identificadora).

Las instancias políticas comunitarias deberían ser capaces de poner de manifiesto el potencial de este sector traduciéndolo en actuaciones políticas. Para conseguir estos fines precisarían de un apoyo muy definido, a través del establecimiento de un entorno jurídico y administrativo favorable a su puesta en marcha y su consolidación en el mercado, desde todas las instancias (Estados miembros las regiones y autoridades locales). Esto conlleva la integración de la dimensión cultural en las otras políticas comunitarias.

Junto a estos problemas, hay que manifestar la importancia de la educación y la formación artístico-cultural de la población europea y su relación con la cuestión de la igualdad de acceso a la cultura como fruto de una herencia común y de una identidad europea, ofreciendo al ciudadano europeo la oportunidad de conocer su propia cultura y la de otros pueblos. Esto supone la importancia de la formación de cuadros especializados en la gestión cultural (fundamentalmente jóvenes), que han de trabajar en el ámbito de la cultura y el patrimonio según las demandas del mercado y los estudios de público, que sostengan y reaviven la demanda cultural europea.

De esta manera será posible promover acciones culturales innovadoras, basadas en el turismo cultural, que promuevan zonas culturalmente muy ricas, pero con dificultades económicas de desarrollo. Estas acciones tienen que estar centradas en lo local y basadas en una cooperación interregional.

\section{DIFUSIÓN E INTERPRETACIÓN DEL PATRIMONIO}

Los programas de interpretación deben presentar los diferentes niveles de significación del patrimonio (universales, nacionales o locales) de manera relevante y accesible para los propios habitantes de la localidad y para los visitantes, mediante métodos de presentación atractivos y actuales, medios informativos, tecnología y desarrollo personal, proporcionando información histórica, cultural y del entorno natural (Carta del ICOMOS). Los intérpretes y guías de sitio deberían ser formados entre personas de la propia comunidad local, e incrementar así la presencia de esta población en la presentación e interpretación de sus propios valores culturales, y de esta forma arlos interesarlos en el cuidado y la conservación del mismo.

Pero ¿en qué consiste la interpretación?: 
La interpretación del patrimonio surge como respuesta al aumento de la demanda y consumo de diferentes elementos del pasado y de la necesidad de la protección del legado cultural y/o del entorno medioambiental. Puede decirse que forma parte en la actualidad de una serie de conceptos sociales y se ha convertido en una importante herramienta de difusión del patrimonio histórico (Sivan, 1998).

Existe una gran confusión terminológica sobre la interpretación del patrimonio. Este término fue introducido en España a fines del pasado siglo XX procedente de Estados Unidos, donde había nacido a fines del siglo XIX en relación con la atención a los visitantes de los parques nacionales, aunque esta función de transferencia cultural de contenidos patrimoniales es bastante antigua.

Para Freeman Tilden (1957) es una actividad educativa que pretende revelar significados e interrelaciones a través del uso de objetos originales, por un contacto directo con el recurso o por medios ilustrativos, no limitándose a dar una mera información de los hechos.

Para Don Aldridgge (1973) es el arte de explicar el lugar del hombre en su medio, con el fin de incrementar la conciencia del visitante acerca de la importancia de esa interacción, y despertar en él un deseo de contribuir a la conservación del medio ambiente.

Para Bob Peart (1977) se trata de un proceso de comunicación diseñado para revelar al público significados e interrelaciones de nuestro patrimonio natural y cultural, a través de su participación en experiencias de primera mano con un objeto, artefacto, paisaje o sitio.

Yorke Edwards (1980) opina que posee cuatro características que hacen de ella una disciplina especial: comunicación atractiva, información concisa, en presencia del objeto en cuestión y su objetivo es la revelación de un significado.

Paul Risk (1982) es la traducción al lenguaje técnico y a menudo complejo del ambiente, a una forma no técnica, sin por ello perder su significado y precisión, con el fin de crear en el visitante una sensibilidad, conciencia, entendimiento, entusiasmo y compromiso.

Para la AIP (1999) es el arte de revelar in situ el significado del legado natural, cultural o histórico, al público que visita esos lugares en su tiempo de ocio.

En realidad es o debería ser un servicio público que pone en valor unos elementos del patrimonio para uso y disfrute del público en su tiempo de ocio, como derecho de los 
ciudadanos y deber de la administración. También puede constituir la interpretación una fuente de ingresos y/o beneficios sociales más o menos directos. Este hecho nos acerca a la cuestión de la interpretación como instrumento de gestión del patrimonio, aunque la rentabilidad estas actividades interpretativas sean que discutibles a nivel financiero, y más plausibles a nivel de política cultural, pues a largo plazo su rentabilidad estará en el aspecto actitudinal, además de la aportación hacia la creación de una imagen de la administración o de los patrocinadores. Tengamos presente que estas acciones van dirigida no al público entendido y experto, y por ello motivado, sino al público en general (turistas) y al que hay que conseguir sensibilizar.

Se pueden resumir en tres los objetivos de la interpretación:

- $\quad$ ILUSTRAR.- dar a conocer nuestro pasado y las realizaciones actuales con sentido artístico, valorando el patrimonio desde una experiencia valiosa y/o agradable y concienciando al usuario.

- $\quad$ PROTEGER.- ya que el uso controlado, por un lado, y la valoración dan lugar a la toma de conciencia de la necesidad de su protección y conservación.

- CAPITALIZAR.- pues mediante el conocimiento y la valoración se obtienen de forma directa o indirecta que la comunidad aporte recursos directa o indirectamente para su conservación.

Un aspecto importante de la acción interpretativa es aparición de una serie de elementos reconstruidos de algunos elementos del bien que se interpreta o presenta, de forma que los elementos reconstruidos e incluso los inventados son captados por los visitantes formando parte de la realidad, en definitiva se trata de la diferenciación entre lo auténtico y lo imaginario. Por lo tanto es importante que en la presentación se equilibren las reconstrucciones y técnicas de presentación con los elementos reales y auténticos del bien que se presenta a los visitantes.

Pero es importante no confundir la presentación museológica con la presentación interpretativa o in situ, se trate del elemento patrimonial del que se trate (desde un monumento aislado hasta un conjunto), pues las dos situaciones son distintas y precisan de tratamientos diferenciados, aunque haya elementos comunes.

En el caso del museo el objeto expuesto se halla descontextualizado, sin su valor intrínseco y convertido en un objeto protegido, pero aislado. Pero cuando es presentado in situ se encuentra a merced de algunas inclemencias y peligros por el propio uso, pero con un valor contextual muy acentuado. Es necesario pues diferenciar los tratamientos conservadores como los mecanismos interpretativos en un caso y otro (Sivan, 1998).

Un concepto distinto y alternativo a los parques temáticos, ahora tan de moda, 
son los conjuntos interpretativos, que se centran en los “territorios-museo". La estrategia interpretativa empleada en estos elementos abarca una oferta cultural y turística muy amplia que interactúa con múltiples sectores entre los que se diversifican los recursos necesarios para la propuesta de dinamización, valoración y puesta en uso del patrimonio de la zona. La aparición del conjunto interpretativo conlleva un proceso de percepción en el que el territorio se convierte en producto cultural, que se transforma de esta forma en yacimiento cultural en el que se han depositado las aportaciones culturales de los habitantes que lo han ocupado a lo largo de la historia. Ese conjunto de elementos culturales necesita ser dotado de un sentido, esa es la función del conjunto interpretativo, éste se puede resumir en:

Un sistema de representación que utiliza diversos procedimientos: impreso, centros de acogida e información, señalización, interpretación, etc.

Una compleja oferta cultural que abarca todos los elementos patrimoniales en los que se ofrece posibilidades varias.

Su objetivo es permitir al visitante conocer el territorio contrastando lo que conocía con lo que descubre en el conjunto interpretativo.

A nivel funcional este se compone de:

- Un centro de interpretación, acogida e información que sirve de punto de partida y arranque de la oferta interpretativa.

- Los ámbitos temáticos o conjuntos de elementos patrimoniales e interpretativos.

- Los programas de animación de carácter permanente y/o estacional dirigidos a públicos determinados para motivarles y hacerles partícipes de las experiencias (Miró, 1997).

Las actividades culturales relacionadas con el patrimonio suponen siempre cuestiones relativas al uso del patrimonio, lo que lleva siempre a los aspectos interpretativos del patrimonio, entendiendo como interpretación el arte de dar a conocer, hacer accesible y explicar el sentido y el significado de las cosas. Existen varios niveles de interpretación: desde el arqueólogo frente a un artefacto hasta los grandes planes interpretativos, y dentro de estos niveles hay, a su vez, varios grados de complejidad diferentes, pero implica siempre un acto comunicativo (Miró, 1997).

La interpretación, relacionada con el uso social del patrimonio, se convierte en un instrumento de planificación y forma parte de unas estrategias de desarrollo, que van más allá del simple entretenimiento intelectual y constituye una parte importante 
de la base de una política de comercialización y explotación turística, en el marco de un plan de actuación que responda a las demandas de uso planteadas; y también implica una toma de decisiones sobre aspectos variados (conservación restauración, mensajes, accesibilidad, etc.), que debieran ser enmarcados en unos planes de interpretación para poder desarrollar políticas de patrimonio coherentes.

Esta oferta patrimonial siempre se enfrenta tres cuestiones básicas:

- Relación patrimonio-identidad.

- Relación patrimonio-economía.

- Relación patrimonio-sociedad.

La atención a estas tres cuestiones relacionadas con la interpretación implica un análisis de recursos y demandas, concretarlos en objetivos y actividades que respondan a necesidades y demandas, y, finalmente, redactar los programas de actuación en base a los dos apartados anteriores y que se estructurará en tres ámbitos: comunicación, exposición y explotación.

Respecto del primero, las acciones que lo desarrollan podrían ser:

- conocer la actitud de la población de la zona sobre la actuación.

- inventariar los recursos patrimoniales.

- evaluar la audiencia y las dificultades/atractivos.

- calcular los recursos financieros y humanos disponibles.

En cuanto a la segunda fase o elaboración se pueden realizar las siguientes acciones:

- fijar los objetivos económicos, sociales y de gestión del patrimonio.

- determinar los temas y argumentos interpretativos que guíen la actividad interpretativa.

- definir los sistemas de presentación en función de los objetos patrimoniales y del público y presupuesto.

- diseñar los servicios complementarios relacionados con la atención a visitantes y a su comodidad.

- determinar la gestión de los servicios.

Respecto de la tercera fase, en la que ya se redactan los planes de interpretación hay que tener en cuenta que con la interpretación se trata de que el visitante tome conciencia del valor de los elementos patrimoniales y de la necesidad de su protección y conservación para generaciones venideras. 
Son varios los momentos que forman la acción interpretativa sistemática y planificada con un mínimo rigor:

- Diagnóstico de la realidad: mediante el cual se deben averiguar los fines, los sujetos y los efectos que sobre el ente patrimonial puedan tener esa acción interpretativa.

- Planificación interpretativa que consiste en la formulación de los objetivos, y la consideración de los recursos, limitaciones y potencial interpretativo.

- Realización de equipos y programas.- fase en la que se deben realizar los programas y construir los materiales y equipamientos.

- Presentación del patrimonio, que es la ejecución del plan interpretativo previamente elaborado.

- Evaluación, según el plan previsto, que aplica estrategias evaluadoras para conseguir los datos convenientes y que se traducirá en la fase siguiente.

- Retroalimentación, que consiste en incorporar al programa los datos obtenidos en la evaluación (Morales, 1998).

Pero hay que tener muy presente que la más acabada presentación jamás podrá reemplazar el disfrute genuino del elemento patrimonial y su contexto. No se puede presentar o interpretar todo, hay que dejar al visitante que participe en unas actividades que le permitan enfrentarse y descubrir su pasado tal como se le aparece a sus sentidos (Martin, 1998).

La desaparición de los diseños curriculares educativos de áreas de conocimiento, como la filosofía, el latín, la historia, la historia del arte en la enseñanza media, debilita la formación de la ciudadanía en sus aspectos humanísticos, lo que sólo puede conducir a la regresión hacia ámbitos de intolerancia, el consumismo y la deshumanización.

Y, desgraciadamente, estos aspectos culturales anteriores serán los que informen al público que va a acceder a la difusión del patrimonio en los años próximos. Este público medio, con recursos económicos más que suficientes, que sufrirá carencias intelectuales propiciadas por unos contenidos instructivos que lo alejan del interés y capacidad de comprensión de los contenidos de una difusión del patrimonio de corte clásico. Por otra parte estará el neo-proletariado audiovisual, segregado económicamente y por sus niveles instructivos del aprecio de la belleza (Colón, 1998), pero que precisarán de una tarea de difusión, en una sociedad que quiera ser medianamente justa y alcanzar niveles correctos de bienestar, y tareas educativas compensatorias que corrijan estas desigualdades.

A ese público se pretende transmitir EL PATRIMONIO. Pero entendido en sus aspectos naturales y culturales, aunque teniendo presente una serie de consideraciones 
como las referidas a las relaciones del público estos dos aspectos del patrimonio. Mientras que respecto del patrimonio natural, la valoración del público consiste en considerarlo un elemento clave en la supervivencia de nuestra especie y como lugar de disfrute, sobre todo en el caso del visitante procedente de ámbitos urbanos, lo que facilita la comprensión de las medidas conservacionistas. Respecto del patrimonio cultural hay unas relaciones más complejas, pues en este caso la "conservación ha primado sobre función y uso" y, por otro parte, muchos de sus elementos aparecen fuera del contexto de su creación, función y utilidad. Además, estos lugares donde se muestra el patrimonio suelen estar convertidos en espacios sacralizados por un uso comercial-museístico a los que se puede acceder sólo previo pago. Esta descontextualización aleja a la población de sus señas identificativas y de su consideración como fuente de disfrute, aunque por otra parte garantiza su conservación, tremendo dilema.

En este ámbito el receptor de la acción difusora, y las condiciones de su recepción, se hallan poderosamente influenciados por el mundo de la televisión pues ésta traslada la acción comunicadora "del contexto de la palabra (hablada o radiotransmitida) al contexto de la imagen", de forma que el acto visual está sustituyendo al hecho de entender-comprender. Todo ello tiene lugar en un ámbito de lucha por la audiencia en la que la calidad de los programas es inversamente proporcional al número de espectadores casi siempre (Colón, 1998).

\section{La explotación del Patrimonio}

Hay que tener presente que el Patrimonio es uno de los pocos recursos totalmente públicos que existen en nuestras sociedades, pues mantiene un carácter público, tanto como objeto de disfrute por la sociedad, como por ser fundamento de investigación para el conocimiento; en cambio su explotación si puede ser compartida entre el sector público y el privado, aunque respetando los límites marcados por la investigación, protección y conservación.

Este uso y disfrute del Patrimonio, teniendo en cuenta una serie de variables, para poder realizarse por medio del turismo patrimonial debe cumplir al menos estas tres condiciones:

- Una oferta cultural diversificada.

- Una oferta turística específica.

- Sensibilización de los visitantes.

El límite de cualquier proyecto cultural que tenga al Patrimonio como factor de desarrollo, comparado con un proyecto turístico de ocio y rentabilidad monetaria, consiste en llevar al público el patrimonio histórico, con sentido integrador por medio 
de labor de difusión, para ello hay que diferenciar fases y públicos. A nuestro modo de ver la difusión consiste en el conjunto de acciones encaminadas a poner el conjunto del patrimonio al servicio de la ciudadanía para su uso y disfrute, pero en un marco de comprensividad y de generación de actitudes positivas hacia el propio patrimonio histórico.

Esta gestión integral del patrimonio, en el marco de las actividades turísticas, se convierte en el sector más sensible desde el punto de vista de la concienciación de la ciudadanía, y al mismo tiempo se configura como el menos potente y experimentado para producir rentabilidad monetaria en el ámbito del desarrollo social y económico, frente a otros sectores y presiones. Por lo tanto, en el momento de introducirse en la dinámica del desarrollo social y económico a través del turismo se deben mantener ciertas cautelas, pero sin llegar a negar sus importantes posibilidades.

Durante los últimos tiempos, el escenario económico y social de la mayoría de los países desarrollados ha venido caracterizándose por varios factores, los cuales no han favorecido en modo alguno el auge de las actividades empresariales vinculadas con el turismo rural.

Las nuevas iniciativas empresariales orientadas al turismo rural, puestas en marcha en la provincia de Huelva, han contado con el apoyo de dos instrumentos institucionales de desarrollo rural:

Iniciativa Comunitaria LEADER II y Programa Operativo PRODER.

Según los valores tomados de la Iniciativa LEADER II, en las últimas actuaciones en la provincia de Huelva, llegamos al resultado que se muestra en la siguiente tabla. 
Tabla 1. Estadística relativa a los programas LEADER II y PRODER

\begin{tabular}{|c|c|c|c|c|c||}
\hline \multirow{2}{*}{} & \multicolumn{3}{|c|}{ LEADER II } & \multicolumn{2}{c||}{ PRODER } \\
\cline { 2 - 6 } & $\begin{array}{c}\text { Cuenca } \\
\text { Minera }\end{array}$ & $\begin{array}{c}\text { Andévalo } \\
\text { Occidental }\end{array}$ & $\begin{array}{c}\text { Sierra de } \\
\text { Aracena }\end{array}$ & Condado & Costa \\
\hline $\mathrm{N}^{0}$ municipios & 7 & 16 & 28 & 18 & 7 \\
\hline Superficie $\left(\mathrm{km}^{2}\right)$ & 640 & $2.650,2$ & 3.016 & $1.888,6$ & 947 \\
\hline $\mathrm{N}^{0}$ habitantes & 20.247 & 42.687 & 42.020 & 96.108 & 100.214 \\
\hline Tasa de desempleo & $35 \%$ & $23,7 \%$ & $31 \%$ & $11 \%$ & $10 \%$ \\
\hline
\end{tabular}

Elaboración propia a partir de: http://redrural.tragsatec.es/web/default.asp

Como podemos apreciar, se trata de zonas rurales, con alto índice de desempleo (aproximadamente un 30\% de la población activa) y escasa tradición empresarial.

También cabe destacar que si la superficie geográfica que abarca el LEADER II es dos veces la del PRODER, la relación en cuanto a población es la inversa, o sea, el PRODER duplica a la del LEADER II. Debido esto, entre otras causas, al éxodo rural que las zonas menos desarrolladas y más alejadas de núcleos urbanos están padeciendo en la actualidad.

O bien la distribución de los emprendedores por el nivel de estudios y formación de la siguiente figura: 
Figura 2. Distribución de los emprendedores en relación al nivel de formación

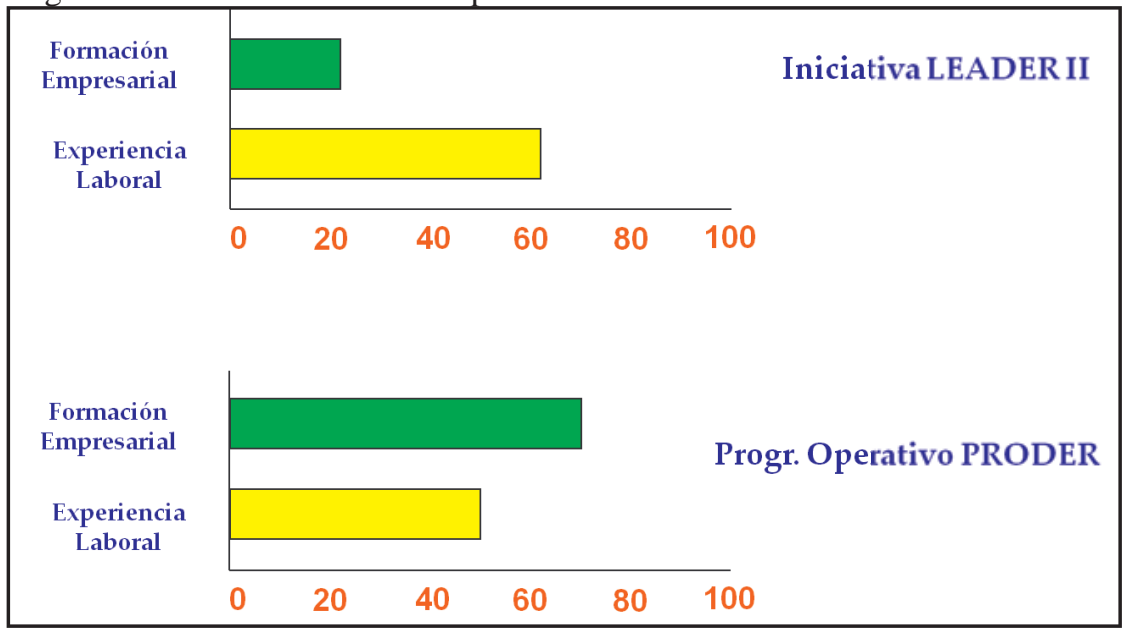

Figura 3. Distribución de los emprendedores en relación al nivel de estudio

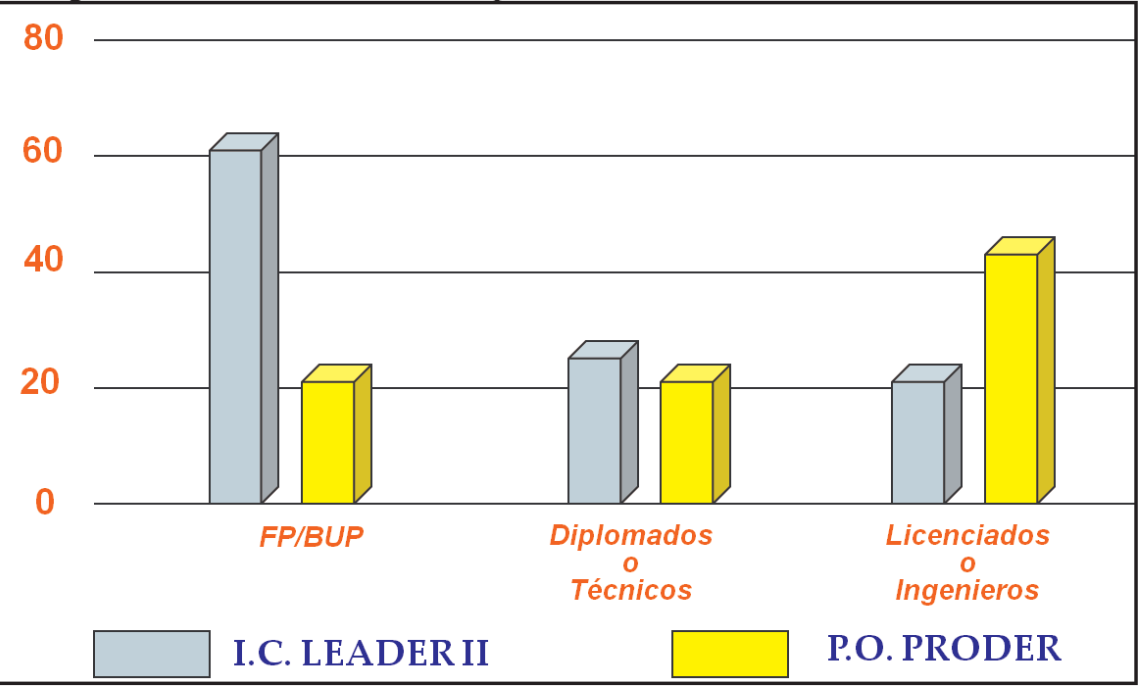

Elaboración propia a partir de: http://www.juntadeandalucia.es:9002/ 


\section{CONCLUSIONES}

El Andévalo onubense, una de las comarcas más afectadas por el declive de la minería, se ve envuelta en una tesitura de buscar nuevas fuentes de empleo para la potenciación de su desarrollo local. Actividades ligadas al turismo endógeno y, sobre todo la recuperación del patrimonio minero-industrial se convierten en nuevos yacimientos de empleo, en una zona que siempre ha vivido por y para la mina. La puesta en marcha de programas comunitarios como el LEADER han sido y serán la base para llevar a cabo estas iniciativas de creación de empleo, fomentando el turismo local, así como la creación de un asociacionismo que pueda poner en valor el rico patrimonio de la comarca en toda su extensión, desde la creación de museos, centros de interpretación hasta el turismo rural aprovechando la puesta en funcionamiento de los poblados mineros como núcleos de interpretación de la historia minera de la provincia.

\section{BIBLIOGRAFÍA}

- Aldridgge, D. (1973): Mejora de la Interpretación de los Parques y la Comunicación con el Público. UICN (Ed.). Segunda Conferencia Mundial sobre Parques Naturales: Yellowstone Grand Teton, EEUU18/27-IX-1972. Informe $n^{\circ} 2$.

- Colón, C. (1998): "Necesidad de la belleza. Notas sobre la difusión del Patrimonio en la sociedad de la comunicación masiva”. Boletín del Instituto Andaluz del Patrimonio Histórico, n 25, pp. 114-119. Sevilla.

- Martín, M. (1998): "El espíritu de la época. Modernización o posmodernización del vínculo entre el patrimonio y los ciudadanos”, Boletín del Instituto Andaluz del Patrimonio Histórico, n² 25, pp. 120-129. Sevilla.

- Martín, M. (2001): Reflexiones críticas sobre Patrimonio, Turismo y Desarrollo Sostenible.(www.arq.com.arlcomurnidad/index/cfm?nro-2-126\&=masinfo,cfm) Conferencia presentada en las Jornadas de Priego, Turismo, patrimonio y desarrollo. Priego de Córdoba.

- Miró I Alaix, M. (1997): “Interpretación, identidad y territorio. Una reflexión sobre el uso social del patrimonio", en Boletín del Instituto Andaluz del Patrimonio Histórico, ${ }^{\circ}$ 18, pp.33-37. Sevilla.

- Morales Miranda, J. (1998): "La interpretación del patrimonio natural y cultural. Todo un camino por recorrer”, Boletín del Instituto Andaluz del Patrimonio Histórico, n 25, pp. 150-158. Sevilla.

- Peart, B. (1977): "Definition of Interpretation". Association of Interpreters Naturalist Workshop, Texas A \& M. University.

- Pérez López, J.M., Romero Macías, E. M., Aguilera Collado, E., Aguilera Carrasco, E., Ruiz Ballesteros, E. (2003). Informe BIC sobre la Cuenca Minera de 
Riotinto para su declaración como Sitio Histórico PH: Boletín del Instituto Andaluz del Patrimonio Histórico, ISSN 1136-1867, Año nº 11, Nº 45, págs. 43-50

- Risk. P.H. (1982): “The Interpretative Talk” en G. SHARPE (ed.): Interpreting the Environment. Wiley \&Sons. Inc. Londres.

- Romero Macías, E.M., Pérez López, J.M.; Aguilera Carrasco, R. (2010). El patrimonio minero-industrial de Tharsis y su repercusión en la Comarca del Andévalo onubense. De Re Metallica, 14, 2010 pp. 23-33. C Sociedad Española para la Defensa del Patrimonio Geológico y Minero. ISSN: 1577-9033

- Sivan, R. (1998): "Diálogo con el pasado. Comunicar el legado. Reflexiones sobre la presentación del Patrimonio in situ", Boletín del Instituto Andaluz del Patrimonio Histórico, n 25, pp. 148-149. Sevilla.

- Tilden, F. (1957): Interpreting Our Heritage. The University of North Caroline Press. Chapel Hill.

- Yorke Edwards, R. (1980): The Land Speaks. Organizing and Running an Interpretation System. 2' Ed. The National and Provincial Parks Association of Canada. Golden, Brithis Columbia.

Recibido: 17/08/2010

Aprobado:01/11/2010

Arbitrado anonimamente 